\title{
Title: Gaining knowledge about Resilient Therapy: how can it support kinship carers?
} Authors: Lindsay Hill* and Angie Hart

Dr. Lindsay Hill*, School of Applied Social Science, School of Social Work, University of Brighton, Mayfield House, Brighton. UK BN19PH.

Professor Angie Hart, School of Health Sciences, University of Brighton, Centre of Health Research, Mayfield House, Brighton, UK. BN19PH. UK.

*Correspondence to Dr. Lindsay Hill, School of Applied Social Science, School of Social Work. University of Brighton, Brighton. UK. BN19PH.email: lindsay.hill@ brighton.ac.uk

\begin{abstract}
The research reported on here examined the utility of a multi-dimensional model for operationalising the findings from a research-informed approach known as Resilient Therapy (RT). The approach is designed to support practitioners, carers, parents and young people in contexts of multiple disadvantages. Seven kinship carers and six children were involved in collaborative action research. Kinship carers met together, on eighteen occasions over a period of fifteen months, to learn about RT and explore how they might draw on the approach to inform their care of children. Children were interviewed on two occasions. Learning arising from the research suggests the importance of introducing RT as a collaborative model that builds opportunities for reflection and action. Carers are supported to find their own solutions, based on an understanding of their relationships with children, children's relationships with them and with others in their network. It is an approach which is attentive to what families do and views family practices as emerging in complex ecological systems. The study is located in an inequalities-informed conceptualisation of resilience research. Findings reinforce the importance of understanding resilience-building as a process which
\end{abstract}


parents/carers/practitioners and young people can facilitate, but also one that must be attentive to the socio-economic systems around families.

Key words: Kinship Care, Resilient Therapy, Resilience, Inequalities, Action Research.

\section{Introduction}

This UK-based research was undertaken in the context of a growth in the use, by social workers, of formal kinship care placements for children who are unable to live with birth parents. Many of these children have experienced abuse and neglect and research has identified that their needs are likely to be as great as those of children who are looked after in foster care (Aldgate, 2009: Farmer and Moyers, 2010). However the support needs of kinship carers, many of whom are grandmothers, have been largely overlooked (Hunt et al., 2008; Hunt and Waterhouse, 2012). Hunt and Waterhouse suggested that to get the services they need kinship carers have to be "knowledgeable, confident, articulate, assertive and persistent" (2012:442). How to support kinship carers who do not easily fit this description is an important issue to address.

Research suggests that interventions which engage parents/carers, including those who are less likely to be assertive and persistent, as active agents of change are helpful. Through processes that involve knowledge exchange these interventions can support people's capacity to access resources and mediate stress. For example, Ramos et al. (2010) found that enabling parents to learn about children's mental health increased their attentiveness to children and encouraged them to access resources. Key messages from this and other studies highlight the importance of engaging with parents/carers and children as active participants in the process of learning and change (Featherstone et al., 2012; Rupert and Mayberry, 2009). A further context for this research is the growing interest in the use of resilience-based approaches in health and social care (Daniel 2008, Daniel 2012) and education (Hart and Heaver 2013a). 
Accordingly, this study explored with kinship carers their experiences of learning about Resilient Therapy (RT) and of trying to integrate ideas into their parenting practices. Interviews with the children were designed to gain an insight into children's views of what was helpful to them in enabling them to navigate the challenges of everyday life.

\section{Defining resilience}

Numerous definitions of resilience require experiences of adversity to be followed by some measure of positive outcome (Zlokoski and Bullock, 2012). Since social workers work with children and adults who have experience of adversity, the connection between this and positive outcomes has an understandably hopeful attraction. However the concept of resilience in social work practice has become increasingly challenging for practitioners. The historical origins of resilience are in developmental psychology, which is critiqued for having taken insufficient account of the impact of social and structural positioning on people's lives (Burman, 2008). Early efforts to identify the reasons why some children and adults appeared to be able to manage adverse experiences, whilst others were overwhelmed by them, focussed primarily on what were then regarded as personal qualities such as autonomy and self-esteem Resilience researchers had by the mid 1980s begun to develop a more ecologically-informed understanding of resilience as a process influenced by a complex interplay of personal, familial and political factors( Brooks and Goldstein 2006, Masten 2007). However, the popular usage of the term has not changed in line with this. Researchers have observed that in some social work contexts it is still used to refer to the personal qualities of a child, young person or their parent/s (Daniel, 2012; McMurray et al., 2008). This connection between resilience and ideas of "rugged individualism" is regarded by critics as having been strengthened by the increasing use of the term in Government policy, not only in the UK but also in other Westernised democracies (Bottrell, 2009:326). As part of a neo-liberal discourse 
the term can be used to communicate to families that they are responsible for managing their own disadvantage (Parton, 2014).

The principles underpinning the RT approach firmly reject the notion that resilience can be viewed solely as an individual characteristic of a child or adult. Building on the work of Prilleltensky and Prilleltensky (2005) and Hart at al. (2007), Aranda and Hart (2014) argue that the social and economic adversity that children and adults may be experiencing will have an important influence on their ability to access and use the resources that are needed to support what RT refers to as “resilience-enhancing processes' (Hart et al., 2007:4). They argue that findings from resilience research need to be applied in a way that takes account of the unique circumstances of the child with an understanding of the broader determinants of inequality. Aranda and Hart (2014) explore resilience-based practices that also attempt to change the actual context of people's wider experience. They draw on empirical data to demonstrate how some practitioners "tinker" with the broader determinants of inequality operating in their environment. Such an approach towards operationalising the findings of resilience research offers an opportunity for social workers to reconsider their understanding of the concept of resilience. This is important because many families report that their experiences of living with poverty and discrimination are compounded when they become involved with child welfare services (Green et al., 2008; Gupta, 2015). Evaluations of social work assessments also consistently highlight the lack of attention paid to the influence of environmental factors (Burgess et al., 2014; Gupta, 2015; Gupta et al., 2016).

\section{Resilient Therapy and the Resilience Framework}

The Resilient Therapy approach towards operationalising the findings from resilience research emerged from collaboration between academics, practitioners and parents of children with disabilities. In 2007 a book entitled Resilient Therapy was published (Hart et 
al.). This was followed by further publications and related outputs, many of which have been co-produced with young people and parents/carers who have experienced challenges in their lives (www.boingboing.org.uk). These outputs speak to the varied ways in which people experience adversity. They articulate the efforts which people make to find a way through the difficulties they encounter in everyday life and what they have found supportive in their attempts to navigate their troubles. This emphasis on diversity, not only in terms of experience of adversity but also of what people find helpful, is a central feature of an RT approach. In recent years a community of practice approach has enabled RT to be adopted and/or developed by health, social care and education practitioners, service users and other community practitioners in the UK and beyond (Hart et al 2013b).

RT is underpinned by four principles, known in its lexicon as "noble truths". It seeks to Conserve the strengths of what is happening in people's lives and recognises people as being interdependent. Enlisting the help and support of others, whether they are family/friends or more formal services, is regarded as being a key element of RT-informed practice. Accepting and Commitment are also underpinning principles. Accepting in the context of RT is future orientated; the focus is on movement towards futures in which everyday troubles can be navigated in a way that is helpful to the child and the wider network. Commitment signifies that RT recognises that in the context of multiple disadvantages there are unlikely to be any quick fixes.

Resilience-informed practice requires that practitioners work with these underpinning principles. This can be challenging for social workers who find themselves working in organisational systems which undermine their capacity to develop meaningful relationships with families. However, recent calls for a more relational base for social work practice sit well with the underpinning principles of the RT approach, as do constructive and solutionbased approaches (Gupta et al., 2016; Munro, 2011; Parton and O'Byrne, 2000). The RT 
approach is summarised in Figure 1 in the form of what has become known as the Resilience Framework.

\section{FIGURE 1 ABOUT HERE}

The five broad areas of Basics, Belonging, Learning, Coping and Core Self have been constructed as a way of encompassing the everyday practices that can make a difference for children and young people. The terminology used is simple, some might see it as vague. However in books and articles written on RT there is further elaboration of each term (or 'remedy' in the popular lexicon of RT), with practice examples and tips on how to develop the specifics. The aim is to try to democratise the helping process by using language around which meaning can be negotiated between children and parents/carers and practitioners. The approach recognises that a person can navigate troubles in a number of ways and that there are no right answers to the complex challenges that human beings may encounter. RT also recognises that people are strongly influenced by structures and institutions that give rise to how realities are experienced. Each of the five domains contains suggestions, rather than definitives, about what might be done to support a young person with their particular day-today experiences. RT encourages narratives and re-interpretations of situations in order to discover new forms of action. The research which is the subject of this article set out to explore with a group of kinship carers their views concerning the value of the RT approach.

\section{The study}

A letter was sent to all kinship carers known to a Children's Services Family and Friends Team in England, inviting them to attend a meeting to hear about the proposed research. Ten kinship carers attended the meeting and seven of these said that they would like to be 
involved in the research. Those who declined said that they did not feel able to make a long term commitment to the research. The kinship carers who did join the research group were, between them, looking after nine children ranging in age from 5-18 years. The average length of time they had been looking after these children was 4 years. Four of the seven kinship carers were maternal grandmothers. One grandfather and an aunt also took part. One group member had been a family acquaintance of one of the children. Whilst the group was relatively small, members encompassed multiple identities which they described in different ways. The use of pseudonyms was agreed for all participants. Miriam identified herself as " $a$ black African mother, grandmother and asylum seeker". Helen referred to herself as "an older woman, a former business woman and a newcomer to England". Rory spoke of "being a son, a husband, a step grandfather". Gayle used a wheel chair and referred to herself as "not having a disability, being a mother, a daughter and an ex-social care worker". Jean spoke of herself as having struggled with mental health issues and Susan, who was an aunt, spoke of the importance of family: "family is everything to me, it is what I do". Table 1 identifies carers' relationship to kinship care children and the characteristics of those children.

\section{TABLE 1 ABOUT HERE}

These identities and experiences were important and they had an influence on people's choices and actions. The research aimed to uncover what RT refers to as "the effective detail" involved in the day-to-day care of children and the extent to which what was being done could be said to support a resilience-informed approach (Hart et al., 2007:36). Finding ways of concretising the strategies that kinship carers were already using to navigate difficult situations was a key focus. 


\section{Methods}

Ethical Approval for the research was gained from the University and a Local Authority Children's Department. Informed consent was gained from kinship carers and the children they were caring for. The study brought together collaborative action research and the use of visual images with the aim of revealing the everyday experiences and practices of kinship carers. The underpinning philosophy of collaborative action research is that it should aim to open up spaces for communication in which different stories can be heard, and in which the knowledge which emerges can be used by the people involved to help them to take action in order to improve their situation (Heron, 2006). Kinship carers came together as coresearchers of their own practices and the shared cycles of reflection, planning and action, a central feature of action research which were used to frame the process of inquiry (Reason and Bradbury, 2009). There were eighteen meetings of the group, group meetings lasted for approximately two hours. These meetings were facilitated by a University based researcher and a social worker from the Children's Services Family and Friends Team. Photographs that represented everyday activities were brought to the group by kinship carers. They were helpful in enabling people to engage in reflective conversations about their family practices. The group process was important in enabling the development of ideas, concerning how the RT framework might be applied in different family situations. It also built a sense of belonging and trust amongst the research participants.

Six of the children were interviewed on two occasions, by the University based researcher. Three children were not involved in the interviews. Their carers considered that they might be confused and upset by being asked to speak about their experiences. The views of the children who were involved, were used to enable a responsiveness to be maintained with children's experiences of resilience-informed family practices. 


\section{Analysis}

Winter and Munn-Giddings (2001) argue that action research which encompasses a commitment to change should engage with a process of analysis which has the ability to enable an understanding of the processes of change to be brought to the surface. In order to achieve this they suggest that data needs to be interrogated from a number of perspectives. Drawing on the work of Winter and Munn-Giddings (2001), Hart (1995), and Fairclough's (2007) voice-centred relational model, the data were analysed from three different modes of being which Hart describes as "inter-connective", “decentred" and "affective" (1995:215). This involved an extensive reading and re-reading of the data, with the aim of revealing how co-researchers spoke about thoughts, feelings and the impact of socio-economic structures. By developing an explicit framework to apply to the process of data analysis, the aim was to try to make clear the decisions regarding the meaning of the data and their relevance to the study. This is consistent with the epistemological positioning of this research, which argues that all interpretation is social in its nature and that "researchers must ensure that they explain the reasons for their interpretations" (Holland and Ramazanoglu, 1994:133).

\section{Findings}

Findings from this study identified that children valued living within family networks; there was evidence of continuity in terms of schooling and friendship groups. Two groups of siblings had been able to maintain relationships over time. Eight of the children remained in contact with one parent. The use of RT as a lens through which to explore the effective detail of family practices enabled an insight to be gained into processes which informed the ways in which kinship carers and children tried to navigate changing family structures. How troubles in families were understood and responded to was also illuminated. The following sections focus on the domains of the RT framework that were explored in the research. Examples are 
provided of how the use of the RT framework supported alternative ways of thinking about situations and suggested different strategies for trying to manage and enhance everyday relationships with and for children.

\section{Basics}

Research in the field of kinship care has attested to the financial hardship that many kinship carers experience and the impact that this can have on the health and well- being of carers and children (Farmer and Moyers, 2010; Hunt et al., 2008). Discussion of Basics in the group revealed how fears about inadequate income, unsafe housing conditions and ill-health, combined with past experiences and cultural beliefs, influenced how kinship carers tried to deal with the damaging effects of inequalities both for themselves and the children. Miriam spoke of her fears of letting her grand-daughters out of the home and, based on her own experience of her childhood upbringing in Africa, how she expected them to:

"Be quiet, be respectful and do what adults say."

Helen spoke of finding a cleaning job and taking her grandson with her. She also spoke of the conflicts that could arise between them when she felt that food was being wasted. In these attempts to deal with their own fears, they considered that social workers had largely been inattentive to the inequalities they were experiencing. Helen said:

"They came down on me like a ton of bricks refusing to allow me to work." Miriam spoke of being told by social workers that she was being too controlling. She revealed that she had been referred to parenting classes, which she considered were inattentive to her cultural beliefs. These experiences speak to the ways in which professional interventions can compound the inequalities that kinship carers are experiencing, and they highlight the importance of being attentive to the ways in which people try to navigate disadvantage. A focus on the meaning of Basics in group discussion enabled kinship carers to 
begin to make connections between a lack of resources and some of the difficulties they were experiencing. Miriam said:

"Whilst I knew that housing was important I did not realise how it was affecting relationships between me and the girls. Learning about the framework gave me the confidence to challenge the Housing Department. I wrote to my MP. Moving made such a difference to us all."

Miriam's actions, and the outcome, inspired other group members and supported what was referred to in the group as a process of "becoming bold". For Miriam and some other women in the group this involved reframing their gendered expectations of women as quiet and respectful in order to give voice to the need for resources to support the ever changing care needs of children.

\section{Belonging}

The importance of attachment and the value of a secure base is a main discourse in social work. Most practice frameworks hinge on this (Department of Health, 2000; Howe, 1995; Schofield, 2009). RT does this, but also goes further. The RT framework draws attention to the significance for children of both attachments to people and to place in the form of community and organisations. RT recognises that clubs and out of home activities can foster a sense of identity and enable people to connect with experiences that are culturally important for them (Jack, 2015). It is these ideas which are captured in the concept of Belonging. The children in the study were of an age where they experienced more of their life outside of the home and it was important for them to find places in which they could be understood, valued and respected.

In the kinship care literature the complex issues of belonging to extended birth families and estranged or chronically ill parents has been previously raised (Hunt et al., 2008). This was a 
massive issue in the research. In this study kinship carers were aware of the importance of being alert to how relationships were working for children in their wider familial and community networks. Children spoke of the struggles they had to understand why they were not living with parents, the value of friendships and of teachers who were attentive to them and treated them with respect. The words "hard", "fear", "worrying" and "sad" were used by Jack, Alex, Liam and Zac when referring to the behaviour of their mothers. Jack used images of animals to help him express his feelings. He said:

"The bird is sad because he cannot see his mummy."

Older children were more explicit in expressing their concerns about the well-being of their mothers. Alex, whose mother had just been admitted to hospital, talked about her continued use of alcohol and his fears for her future:

"She has got schizophrenia, if she does go on drinking like this, because she is 39 now, I think that she will probably die around 40-42."

Alex's mother did die during the time that the research was being conducted.

The remedies identified in terms of Belonging state that it is important to help a child to make sense of where they have come from and to understand their place in the world, however there are no stock answers to the questions children ask around these issues. In the context of reconstituted family relationships kinship carers admitted to the struggles they had experienced in building relationships with grandchildren, whilst at the same time being mindful of how in doing so they experienced emotional struggles in their relationships with their own adult children. Keeping relationships going with birth parents was a particular challenge. Helen's activities involved visiting and supporting her daughter, reassuring Alex about her ill-health, and determining with him the point at which it would be possible for him to visit her in hospital. Alex was worried about his mum and wanted her to get better. He also asked Helen if her getting better would mean that he would have to go back to live with her. 
The emotional impact of responding to this complexity was evidenced in the group as Helen began to cry about the mother/daughter they had both lost.

Jean struggled to make a decisions about whether in the context of her daughter's escalated alcohol misuse it would be better to stop contact between her and Jack:

"I am not sure that it is a healthy relationship for him [Jack] but I am worried about stopping contact. She will be angry and Jack may not understand and be resentful."

Keeping relationships going with others in the family was not only a challenge for grandparents. Susan was parenting her niece and said that she had felt "upset and jealous" when, after two years of silence, Beth's grandparents had asked to see her. She attributed her ability to step back from her emotions, in order to let Beth go to see her grandparents, to her membership of the group and her learning about RT. Explaining how she had drawn on RT she said;

"I thought, conserve my energy, think of the good times ... Before, I would have stewed on it."

Susan also revealed how receiving a wedding card from the group had excited her and had caused her to experience "a real sense of belonging", which had increased her empathy for Beth. This is an example of how the power of small experiences in the group helped to develop co-researchers' insights into children's experiences.

Co-researchers' discussion of fractured relationships with birth parents speak of the importance and problems of Belonging. Whilst group members could relate to the theoretical importance of promoting continuity and positive experiences in relationships, achieving this involved making difficult decisions, particularly about the process of including and excluding people in the family network. What are being described are not once-and-for-all decisions about how to support children, but decisions that had to be revisited as circumstances 
changed. Decisions were contingent on the behaviour and availability of birth parents, the feelings and needs of the child and co-researchers' own feelings and beliefs about how to balance responsibilities and obligations. Understanding what Belonging means and how to do Belonging was thus a complex activity which often involved making decisions in an atmosphere of heightened emotions. Kinship carers found that the framework could be helpful in enabling them to take a step back from troubling situations to find different ways of responding. Jean explained that following a visit from his mother Jack had become distressed:

"I was beginning to go into his trauma just watching him. I thought: be an adult, deal with this. I have reminded myself, play with him, let's have fun. Before I would have gone to pieces and wept.”

Miriam also said that she was developing strategies which enabled her to avoid being overwhelmed by her own feelings:

"I think it helps me to do things in an organised way; there are times you do not know what you are dealing with. Now I think I am dealing with Coping or Belonging. It helps me to place them.”

\section{Learning}

Recent research has highlighted the importance of educational achievement and has suggested that children in foster care can make better educational progress than vulnerable children who remain with troubled families (O’Higgins et al., 2015). This research attests to the difficulties that kinship carers can experience in having their concerns about children's education being taken seriously. Jean and Miriam had been concerned about bullying and racism in schools and they felt that they had to assert themselves in order to advocate on behalf of children. Jean talked about needing to be a "warrior of life" in order to have her concerns that Jack was being bullied taken seriously: 
"I have been to the school several times they will not accept that other children are picking on him, I feel I have to be a warrior of life just to get my voice heard."

Miriam described the on-going racism that her granddaughter had been experiencing and the struggle that she had had to overcome her own cultural beliefs, in order to be able get the school to take action:

"I come from a culture where women are taught to be calm, respectful and not raise their voices, but there are times when you must put your foot down ... I have to stand up for her because when people give you negative comments like that it destroys your self-confidence."

The majority of co-researchers found it hard to know how best to communicate with teachers, so that whilst they recognised the importance of schooling for the children, they felt largely unsupported in their efforts. The group process enabled them to share ideas and gain support. Helen's strategy of visiting the school at the beginning of each term to make specific requests for support was adopted by other group members:

"I say this is what I can do, this is what I need you to do. I am of an older generation which makes it harder for me to know what teachers expect." Alex, who was just about to move to secondary school, was appreciative of this: "She has got all the things for it ... my school shoes and she reads the papers and is phoning up and asking questions."

\section{Coping}

To recap, the starting point in this research involved finding ways of concretising the strategies that kinship carers were already using to navigate difficult situations. In terms of issues of Coping, this seemed especially relevant. Research with parents whose children are 
subject to child protection plans has identified that professionals or other people working with them often do not recognise the strategies that families are trying to use to cope with adversity (Morris and Burford, 2009). The bringing of photos to the group enabled the kinship carers to speak about everyday encounters with children and discussions in the group enabled a greater awareness of how children try to make sense of troubling emotions. Pictures of a hamster, boxing gloves, family groups, and a Super Mario figure were examples of photos that co-researchers brought to group meetings. Referring to the difficult relationship between her granddaughters, Miriam explained that she had noticed them singing together and had recognised that shared activities could be a source of enjoyment. She had acquired a hamster and felt that the shared task of caring for the pet had strengthened their relationship:

"We have given it the name of Adigo, which in Africa means beautiful girl.

They speak to her each morning and night and it has made such a difference." Miriam expressed amazement that little things could make such a difference and her account enabled the group to connect with the role that pets played in the lives of children. It was another example of how something shared in the group led co-researchers to recognise some of the small things that children were doing that they might helpfully support. Hannah acknowledged that she had not previously thought about how children might use their relationship with pets as a coping strategy and reflected that when Liam had a bad day at school he would sit with the dog:

"Yes I had not thought that you know, that they are talking to the dog." Helen also commented on the value of pets in helping children to develop a sense of responsibility. Their recognition of the value of pets for children as a means of helping to build self-esteem is supported by psychosocial research on pre-adolescent development and children's experiences in the care system (Gilligan 1999; 2000; van Houtte and Jarvis, 1995). 
The discussion also highlighted the importance of being able to capture ordinary mainstream opportunities to support resilience (Gilligan 1999; 2000).

RT reminds us of the importance of enlisting help. In the group, carers also considered how access to professional services could be used to support their efforts. Miriam brought to the group a picture of a rocket and explained how a child psychotherapist had enabled her to help her and her granddaughters become more aware of their emotions:

"We all use the rocket, we say, where are you now... I am on orange, time to calm down."

\section{Core Self}

In the context of RT the notion of Core Self is founded on the concepts of "self-esteem, selfefficacy, confidence and competence" (Hart et al., 2007:122). Co-researchers found it hard to understand the notion of Core Self, suggesting that the framework works better for families when related to tangible, practical issues. However in speaking about what they wanted for the children, they referred to their beliefs about the importance of confidence and being able to make decisions and choices. The Core Self interventions listed by Hart et al. (2007) show themselves in the hopes which group members held for the children and the ways in which some of the children did talk about their own aspirations for the future. Zac talked about his desire to do well in education and go to college, and Alex talked about being able to travel: "I like living with Nan .... she took me to the carnival in London and she organises holidays because she wants me to see the world."

When thinking about Core Self it is important to look back over the activities talked about under the other domains. RT draws attention to the dynamic nature of the model, in that what is done in one area carries the potential to promote confidence and competence in another 
area of a child's life. When carers are sensitive to the emotional life of children they in turn can be seen to be helping the children to learn about themselves and about others.

\section{Discussion}

RT is a multi-dimensional approach towards supporting and developing resilience-informed practice. The research was concerned with creating a space in which kinship carers could be given the opportunity to articulate the challenges they experience in looking after children and the strategies they use to try to support them. Additionally the research was designed to enable kinship carers to explore the extent to which their own coping strategies could be supported and extended through the process of learning about RT. Findings from Hunt and Waterhouse's (2012) research have suggested that carers need to be assertive in order to have their voices heard and difficulties can be compounded because it can be hard to give voice to aspects of things that are important in day-to-day life, because they are familiar and can appear simplistic (Sayer, 2011).

In this context the value of RT in this research was that it enabled co-researchers to have a shared language through which to talk about their family practices. The language of RT resonated with their experiences and it helped them to reflect on and make explicit the RT activities they engaged in on a day-to-day basis. As the research progressed it also became clear that at times of stress and uncertainty, knowledge of RT enabled carers to step back from difficult encounters with children, to consider alternative ways of responding. Their capacity to do this was enhanced by the collaborative nature of the research and importantly the group process. The sharing of caring practices through the lens of RT not only helped kinship carers to recognise the potential value of what they were doing, it also helped them to think about how children might be supported in different ways. The example given of their 
recognition of the role of animals in children's lives, helped them to become more aware of the strategies children were using and how they might usefully support or refocus these.

In line with research which has attested to the complex issues of belonging, which can arise for children in kinship care, this research revealed that children do worry about birth parents who are unwell or absent, and all of the children involved struggled at times to make sense of relationships (Farmer and Moyers, 2010; Hunt, 2008). Co-researchers consistently described care that was rooted in day-to-day interactions with children, and was affected by how both they and the children they were caring for made sense of their relationships with each other. Such accounts of caring and children's experiences of being cared for, support previous conclusions about the physical and emotional work involved in care giving (Barnes, 2012). This speaks to the importance of understanding the effective detail of what is involved in the giving and receiving of care, and how wider networks of family, friends and social institutions, particularly schools, can impact children's needs as well as the capacity of carers to respond.

\section{Implications for social work}

RT is consistent with social work's bio-psycho-social perspective and ecological approaches. However research on social work practice has suggested that insufficient attention is given to the damaging effects of structural inequalities (Featherstone et al., 2014; Gupta, 2015; Gupta et al., 2016). The racism experienced by Miriam's granddaughters, alongside the impact that poor housing had not only on her welfare, but also on the relationship between her granddaughters, highlights the importance of being alert to the impact of inequalities, and of findings ways of working to change the material condition of people's lives. This collaborative research is an illustration of how an RT approach, which incorporates an emphasis on Basics, can offer a useful framework for professionals and families to think 
together about how different elements of RT might be combined or attuned to take resilient action (Aranda and Hart 2015).

RT was developed with the aim of trying to democratise the helping process. This involves an approach where professionals are not there to impose solutions on families. Rather they are there to engage in listening to what families say, and working together with them to identify how, in the context of complexity, changes can happen and what resources are needed. This is an approach that can be used in support groups for kinship carers, foster carers and adoptive parents. Building on the whole family approach (Morris et al, 2008, Morris 2012) social workers could also be encouraged to consider how they might draw on the RT framework in their work with family networks, to explore family practices and support families in the making of resilient moves.

\section{Methodological considerations and need for further research}

This study is located within a wave of resilience research which is being undertaken by University based researchers, focusing on the co-production of knowledge with children and adults who are living in disadvantaged situations (Aranda and Hart 2014). It is a small-scale study and the findings can be built on in a number of ways, for example by exploring together with a wider network of families their ideas about the RT approach and how they might use it to support resilience-building with children. Birth parents have not been directly involved in this research, however they figured prominently in the lives of children and had a huge impact on the emotional lives of co-researchers who were grandparents.

Children were included in a limited way, but their voices provide an additional perspective on what helps in times of complexity. Future research could involve children as co-researchers. Further research could also include the administration of a questionnaire, for example a suitable resilience measure such as Sun and Stewart's (2007), to children pre and post the 
kinship carers' group process. These additions could be of particular value in enabling further insights to be gained on how RT-informed parenting practices are experienced by children. We have argued that an RT approach needs to be implemented collaboratively, in a way that recognises the centrality of relationships in families, and the impact that inequalities can have on the ability to care. A collaborative action research inquiry involving social work practitioners and kinship carers, in which practitioners actively engage with this approach to implementing RT, represents an exciting next stage in the further exploration of what helps us to learn about how to support children in kinship care and their families. It would involve what Miriam referred to, when presenting the findings of this research at a Conference, as:

"Working with kinship carers, not as part of the problem, but as part of the solution".

\section{Acknowledgements:}

A special thanks to the kinship carers and children who generously shared some of the effective detail of their everyday lives and their experiences of learning about the Resilient Therapy Framework. 


\section{References}

Aldgate, J. (2009) 'Living in kinship care-a child centred view', Adoption and Fostering, 33, pp. 51-62.

Aranda, K. and Hart, A.(2014)'"Tinkering with practice theory to generate new ways of thinking about using resilience". Health 19(4) pp355-371

Aranda, K. and Hart, A. (2015) Developing Resilience to Tackle Heath and Social Inequalities. Primary Health Care 25(10) pp 18-24.

Barnes, M. (2012) Care in Everyday Life: An Ethic Of Care in Practice, Bristol, Policy Press. Brooks, R., B., and Goldstein, S.( 2006) Handbook of Resilience in Children. Springer. Bottrell, D. (2009) 'Understanding marginal perspectives: towards a social theory of resilience', Qualitative Social Work, 8(3), pp. 321-339.

Burgess, C., Daniel, B., Scott, J., Dobbin, H., Mulley, K. and Whitfield, E. (2014) Preventing Child Neglect in the UK. What Makes Services Accessible to Children and Families? Watford, Action for Children.

Burman, E. (2008) Deconstructing Developmental Psychology, London, Routledge. Daniel, B.( 2008) The concept of Resilience. Messages for Residential Child Care. Ch.5 in Kendrick, A (Ed) Residential Child Care : Prospects and Challenges. Jessica Kingsley Daniel, B. (2012) 'Resilience as a concept for child welfare and child protection practice', Conference Paper, University of Brighton.

Department of Health (2000) Common Assessment Framework for Children in Need and their Families, London, The Stationary Office.

Fairclough, L. (2007) 'Adapting the voice-centred relational method of data analysis: reading trainees' accounts of their learning on a pilot programme for practitioners working with parents', Learning in Health and Social Care, 6(1), pp. 2-13. 
Farmer, E. and Moyers, S. (2010) 'What factors relate to good placement outcomes in kinship care?' British Journal of Social Work, 40, pp.426-444.

Featherstone, B., Broadhurst, K. and Holt, K. (2012) 'Thinking systemically-thinking politically: building strong partnerships with children and families in the context of rising inequality', British Journal of Social Work, 42(4), pp. 618-633.

Featherstone, B., White, S. and Morris, K. (2014) Re-Imaging Child Protection, Bristol, Policy Press.

Gilligan, R. (1999) 'Enhancing the resilience of children and young people in care by encouraging their talents and interests', Child and Family Social Work, 4(30), pp. 187-196. Gilligan, R. (2000) 'Adversity, resilience and young people: the protective value of positive school and spare time experiences', Children and Society, 14(1), pp. 37-47.

Green, R., Pugh, R. and Roberts, D. (2008) 'Black and minority ethnic parents with mental health problems and their children', SCIE Research Briefing, 29.

Gupta, A. (2015) 'Learning from others: an auto-ethnographic exploration of children and families social work, poverty and the capability approach', Qualitative Social Work Advance Access published December 16, 2015, doi:10.1177/1473325015620946.

Gupta, A., Featherstone, B. and White, S. (2016) 'Reclaiming humanity: from capacities to capabilities in understanding parenting in adversity', British Journal of Social Work, 46, pp. $339-354$.

Hart, A., Blincow, D. and Thomas, H. (2007) Resilient Therapy, London, Routledge. Hart, A. and Heaver, B. (2013a) 'Evaluating resilience based programmes for schools using a systematic consultative review', Journal of Child and Youth Development, 1, pp. 27-53.

Hart, A., Davies, C., Aumann, K., Wenger, A., Aranda, K., Heaver, B. and Wolff, D. (2013b) 'Mobilising knowledge in community-university partnerships: what does a community of practice approach contribute?' Contemporary Social Science, 8(3), pp. 278-291. 
Hart, S. (1995) 'Action-in-reflection', Educational Action Research, 3, pp. 211-232.

Heron, J. (2006) Co-Operative Inquiry Research into the Human Condition, London, Sage .

Holland, J. and Ramazanoglu, C. (1994) 'Coming to conclusions: power and interpretation in researching young women's sexuality', in Maynard, M. and Purvis, J. (eds), Researching Women's Lives from a Feminist Perspective, London, Taylor Francis.

Howe, D. (1995) Attachment Theory for Social Work Practice, London, Macmillan.

Hunt, J. (2008) 'Family and friends care, research and practice', Briefing No. 16, Research in Practice.

Hunt, J., Waterhouse, S. and Lutman, E. (2008) Keeping them in the Family: Outcomes for Children Placed in Kinship Care through Care Proceedings, London, BAAF.

Hunt, J. and Waterhouse, S. (2012) Understanding Family and Friends Care: The Relationship between Need, Support and Legal Status, Oxford, Family Rights Group. Jack, G. (2015) “'I may not know who I am, but I know where I am from” the meaning of place in social work with children and families', Child and Family Social Work, 20, pp. 415423.

Masten, A. ( 2007) Resilience in Developing Systems: Progress and Promise as a third wave arises. Developmental Psychopathology 19(3) 921=930

McMurray, I., Connolly, H. and Preston-Shoot, M. (2008) 'Constructing resilience: social worker's understanding and practice', Health and Social Care Community, 16(3), pp. 299230.

Morris,K.,Hughes,N.,Clarke,H.,Tew,J.,Mason,P.,Galvini,S.,Lewis,A.,Loveless,L.,Becker,S. and Burford, G.( 2008) Think Family: A Literature Review of whole Family Approaches. London Cabinet Office. 
Morris, K. and Burford, G. (2009) 'Family decision making: new spaces for participation and resistance', in Barnes, M. and Prior, D. (eds), Subversive Citizens: Power Agency and Resistance in Public Service, Bristol, Policy Press.

Morris, K.(2012) Thinking Family? The Complexities for Family Engagement in Care and Protection. British Journal of Social Work 42 906-920

Munro, E. (2011) The Munro Review of Child Protection: A Child Centred System: Final Report, London, The Stationary Office.

O’Higgins, A., Sebba, J. and Luke, N. (2015) What is the Relationship Between being in Care and the Educational Outcomes for Children: An International Systematic Review, Oxford, Rees Centre for Fostering and Education.

Parton, N. and O’Byrne, J. (2000) Constructive Social Work: Towards a New Practice, Basingstoke, Palgrave MacMillan.

Parton, N. (2014) The Politics of Child Protection: Contemporary Developments and Future Directions, Basingstoke, Palgrave Macmillan.

Prilleltensky, I. and Prilleltensky, O. (2005) 'Beyond resilience: blending wellness and liberation in the helping professions', in Ungar, M. (ed), Handbook of Working with Children and Youth, London, Sage.

Ramos, B., Burton, G., Penn, M. and Crowe, M. (2010) 'The application of behaviour change theory to family based services: improving parental empowerment in children's mental health', Journal of Child and Family Studies, 19(4), pp. 462-470.

Rupert, A. and Mayberry, D. (2009) 'A “snapshot "of Australian programmes to support children and adolescents whose parents have a mental illness', Psychiatric Rehabilitation Journal, 33(2), pp. 125-132.

Reason, P. and Bradbury, H. (eds) (2009) Handbook of Action Research, London, Sage. 
Sayer, A. (2011) Why Things Matter to People: Social Science, Values and Ethical Life, Cambridge, Cambridge University Press.

Schofield, G. (2009) 'The significance of a secure base: a psycho-social model of long term foster care', Child and Family Social Work, 14(3), pp. 255-266.

Sun, J., \& Stewart, D.E. (2007). Development of population based resilience measure in the primary school setting. Health Education, 107(6), 575-599.

Van-Houtte, B. and Jarvis, P. (1995) 'The role of pets in pre-adolescent psychosocial development', Journal of Applied Developmental Psychology, 16, pp. 463-479.

Winter, R. and Munn-Giddings, C. (2001) The Handbook for Action Research in Health and Social Care, London, Routledge.

Zlokoski, S. M. and Bullock, L. M. (2012) 'Resilience in children and youth', Children and Youth Services Review, 34(12), pp. 2295-2303. 
